\title{
FAKTOR RISIKO KEJADIAN POSTPARTUM BLUES DI KOTA PALEMBANG
}

\section{THE RISK FACTORS OF POSTPARTUM BLUES IN PALEMBANG CITY}

\author{
Intan Kumalasari ${ }^{1}$, Hendawati ${ }^{2}$ \\ Jurusan Keperawatan Poltekkes Kemenkes Palembang, Sumatera Selatan, Indonesia \\ Jurusan Kebidanan Poltekkes Kemenkes Palembang, Sumatera Selatan, Indonesia \\ (email penulis korespondensi: kumalasariintan74@gmail.com)
}

\begin{abstract}
ABSTRAK
Latar Belakang: Penelitian ini bertujuan untuk menganalisis faktor risiko dan angka kejadian postpartum blues di Kota Palembang.

Metode: Penelitian ini merupakan survei analitik dengan rancangan cross sectional. Sampel adalah ibu postpartum yang diambil dari RSI Muhammadiyah, RS Bhayangkara dan RSI St. Khodijah tahun 2017 dengan jumlah 90 orang, menggunakan teknik Proporsional cluster random sampling. Analisis statistik menggunakan uji chi square dan regresi binary logistik.. Intrumen penelitian menggunakan instrument baku yaitu instrument EPDS (Edinburg Postnatal Depression Scale) dengan jumlah soal 10 pertanyaan.

Hasil : Angka kejadian Postpartum blues sebesar 46,7\%. Terdapat hubungan yang signifikan antara paritas ( $p v=0,0005 ; \quad \mathrm{OR}=15,117)$, dukungan keluarga $(p v=0,009 ; \mathrm{OR}=10,996)$, perencenaan kehamilan $(p v=0,006 ; \mathrm{OR}=9,863)$, pendidikan $(p v=0,023 ; \mathrm{OR}=3,656)$ dan kelelahan fisik $(p v=0,029 ; \mathrm{OR}=3,341)$, dengan kejadian Postpartum Blues.

Kesimpulan Terjadinya postpartum blues melibatkan faktor-faktor biopsikososial sebelum dan setelah bersalin. Adanya kerentanan biologis, kerentanan psikologis, situasi stresfull, dukungan sosial kurang, dan strategi yang maladaptif, bersama-sama memberi kontribusi bagi berkembangnya postpartum blues. Dibutuhkan dukungan social, emosional, informasi dan bantuan tenaga bagi ibu postpartum dan mengenali penyebab postpartum blues sejak awal.
\end{abstract}

Kata kunci : Post partum blues, faktor risiko, angka kejadian

\begin{abstract}
Background: This study aimed to determine the risk factors and the incidence of postpartum blues in the city of Palembang.

Methods: This study was analytic survey with a cross sectional design. The sample used is 90 postpartum with Proportional cluster random sampling were from Muhammadiyah, Bhayangkara and Siti Khodijah Islamic Hospital from September $27^{\text {St }}$ to December $06^{\text {St }}$, 2017. Data were analyzed by chi square test and multiple logistic regression. The instrument used EPDS (Edinburg Postnatal Depression Scale) with 10 questions.

Results: The incidence of postpartum blues were 46,7\%. there is a significant relationship with Postpartum blues were parity $(p v=0,000 ;$ OR $=15,117)$, family support $(p v=0,009 ;$ OR $=10,996)$, pregnancy planning ( $p v=0,006 ; O R=9,863)$, education ( $p v=0,023 ; O R=3,656)$ and physical fatigue $(p v=0.029$; $O R=3.341)$.

Conclusion:The incidence of postpartum blues in the city of Palembang is 46\%and parity are the most influential factors for postpartum blues events. The occurrence of postpartum blues involves biopsychosocial factors before and after delivery. Biological vulnerability, psychological vulnerability, stressful situations, less social support, and maladaptive strategies together contribute to the development of postpartum blues. It requires social, emotional, informed and labor support for postpartum mothers and identifies the causes of postpartum blues from the outset.
\end{abstract}

Keywords: Postpartum blues, risk factors, incidence rate 


\section{PENDAHULUAN}

Periode post partum adalah periode yang berhubungan dengan perubahan fisik dan emosional yang intens mengarah pada gangguan kecemasan dan suasana hati. Ada tiga derajat gangguan mood postpartum, yaitu, postpartum blues, depresi postpartum (PPD), dan postpartum psychosis. Postpartum blues adalah gangguan mood yang relatif sering dialami ibu pasca persalinan. ${ }^{2}$ Kondisi ini sering terjadi dalam 14 hari pasca persalinan dan cenderung lebih buruk pada hari ke-3 dan ke-4. ${ }^{3}$

Prevalensi kejadian postpartum blues bervariasi diseluruh dunia. Prevalensi postpartum blues di Tanzania sebanyak $80 \%$ sementara di Jepang 8\%. ${ }^{4}$ Hal ini disebabkan oleh kurangnya kriteria diagnosis dan metodologi penelitian yang berbeda pada masing-masing penelitian, di Asia, prevalensi depresi pasca persalinan antara 3,5\%63,3\% dimana Malaysia dan Pakistan menjadi peringkat yang terendah dan tertinggi. ${ }^{5}$

Angka kejadian postpartum blues di Indonesia secara pasti belum diketahui, namun beberapa penelitian menunjukkan angka kejadian postpartum blues berada di rentang 50-70\%. ${ }^{6}$ Rendahnya angka kejadian postpartum blues dibandingkan negaranegara lain diduga karena budaya dan sifat orang Indonesia yang cenderung "nrimo" dan bersabar menerima apa yang dialaminya, serta masih kentalnya tradisi membantu kerabat yang baru melahirkan, semakin memperkuat keyakinan kalau wanita Indonesia 'kebal' terhadap postpartum blues syndrome.

Postpartum blues ditandai dengan gejalagejala seperti : reaksi depresi/sedih/disforia, mudah menangis (tearfulness), mudah tersinggung (irritable), cemas, nyeri kepala (headache), labilitas perasaan, cenderung menyalahkan diri sendiri, merasa tidak mampu, gangguan tidur dan gangguan nafsu makan (appetite). Gejala-gejala ini mulai muncul setelah persalinan dan pada umumnya akan menghilang dalam waktu antara beberapa jam sampai sepuluh hari atau lebih. Namun pada beberapa minggu atau bulan kemudian dapat

\section{METODE}

Penelitian ini bersifat servey analitik dengan rancangan cross sectional pada ibu postpartum. Populasi penelitian ini adalah seluruh kelahiran di RS Bhayangkara, RS Muhammadiyah dan RSI Siti Khodijah periode bulan September-Nopember 2017. berkembang menjadi keadaan yang lebih berat. ${ }^{7,8}$

Penyebab postpartum blues tidak diketahui secara pasti, tapi diduga dipengaruhi oleh faktor internal dan faktor eksternal. Faktor internal seperti fluktuasi hormonal, faktor psikologis dan kepribadian, adanya riwayat depresi sebelumnya, riwayat kehamilan dan persalinan dengan komplikasi, persalinan section caesarea, kehamilan yang tidak direncanakan, bayi berat badan lahir rendah (BBLR), dan pada ibu yang menyusui dan mengalami kesulitan dalam menyusui serta ibu yang tidak mempunyai pengalaman merawat bayi. ${ }^{9}$

Ibu postpartum blues harus diidentifikasi sejak awal dan ditangani secara adekuat, karena bila tidak diobati akan menempatkan ibu pada risiko penyakit yang berulang dan berdampak jangka panjang terhadap peran ibu yang berhubungan dengan perkembangan emosional dan perilaku anak, serta peran ibu di keluarga. Penanganan Postpartum blues yang tidak tepat dapat berkembang menjadi depresi postpartum atau bahkan gejala yang lebih berat yaitu psikosis. ${ }^{10}$

Untuk itu, sangat diperlukan sistem yang dapat mengidentifikasi kondisi kesehatan ibu selama kehamilan dan masa nifas sehingga gangguan mood pasca melahirkan dapat diidentifikasi sejak dini dan diobati dengan tepat baik dengan terapi farmakologis dan nonfarmakologis. ${ }^{11}$

EPSD adalah salah satu upaya untuk mendiagnosis masalah ibu dengan cepat dan memberikan pengobatan depresi postpartum blues yang tepat untuk meningkatkan kesejahteraan ibu dan bayi, ${ }^{12}$ serta untuk memastikan hubungan yang sehat antara orang tua-anak ${ }^{13}$ Karena itu identifikasi faktor risiko Postpartum blues dengan EPDS adalah penting untuk mendiagnosa masalah kesehatan ibu dan mengurangi prevalensi Postpartum blues. Oleh karena itu penelitian bertujuan untuk menganalisis faktor risiko dan angka kejadian postpartum blues di Kota Palembang.

Sampel terdiri dari ibu postpartum hari ke 2-14 di 3 sebanyak 90 responden dengan teknik Proportionale cluster random sampling. Uji statistik yang digunakan chi-square dan regresi logistik ganda menggunakan metode Backward LR 


\section{HASIL}

Hasil analisis statistik dilakukan uji chi-square dijelaskan pada Tabel 1 dan Tabel 2 menggunakan univariat dan bivariat menggunakan

Tabel 1. Angka Kejadian Postpartum Blues di Kota Palembang (n=90)

\begin{tabular}{cccc}
\hline Postpartum Blues & n & $\begin{array}{c}\text { Persentase } \\
(\%)\end{array}$ \\
\hline 1. Ya & & 46,7 \\
2. Tidak & 42 & 53,3 \\
\hline
\end{tabular}

Tabel 2. Faktor-faktor yang berhubungan dengan Kejadian Postpartum Blues di Kota Palembang $(\mathbf{n}=90)$

\begin{tabular}{|c|c|c|c|c|c|c|c|c|}
\hline \multirow[t]{3}{*}{ Faktor Risiko } & \multicolumn{4}{|c|}{$\begin{array}{c}\text { Kemungkinan terjadinya } \\
\text { Post Partum Blues }\end{array}$} & \multirow{2}{*}{\multicolumn{2}{|c|}{ Jumlah }} & \multirow[t]{3}{*}{ pvalue } & \multirow[t]{3}{*}{ OR $(95 \% \mathrm{CI})$} \\
\hline & \multicolumn{2}{|c|}{ Tidak } & \multicolumn{2}{|c|}{ Ya } & & & & \\
\hline & n & $\%$ & n & $\%$ & $\mathbf{n}$ & $\%$ & & \\
\hline \multicolumn{9}{|l|}{ Umur Ibu } \\
\hline 1. $20-35$ tahun & 41 & 59,4 & 28 & 40,6 & 69 & 100 & \multirow[t]{2}{*}{$0,036^{*}$} & \multirow{2}{*}{$\begin{array}{c}2,929 \\
(1,049-8,176)\end{array}$} \\
\hline 2. $<20$ atau $>35$ tahun & 7 & 33,3 & 14 & 66,7 & 21 & 100 & & \\
\hline \multicolumn{9}{|l|}{ Paritas } \\
\hline 1. Multipara & 33 & 66 & 17 & 34 & 50 & 100 & \multirow[t]{2}{*}{$0,007 *$} & 3,235 \\
\hline 2. Primipara & 15 & 37,5 & 25 & 62,5 & 40 & 100 & & $(1,359-7,701)$ \\
\hline \multicolumn{9}{|l|}{ Jenis Persalinan } \\
\hline 1. Normal & 14 & 45,2 & 17 & 54,8 & 31 & 100 & \multirow{2}{*}{0,260} & 0,606 \\
\hline 2. Sectio Caesaria & 34 & 57,6 & 25 & 42,4 & 59 & 100 & & $(0,252-1,454)$ \\
\hline \multicolumn{9}{|l|}{ Komplikasi/Penyulit } \\
\hline Persalinan & & & & & & & & \\
\hline 1. Tidak Ada & 30 & 63,8 & 17 & 36,2 & 47 & 100 & \multirow[t]{2}{*}{$0,037 *$} & 2,451 \\
\hline 2. Ada & 18 & 41,9 & 25 & 58,1 & 43 & 100 & & $(1,048-5,730)$ \\
\hline \multicolumn{9}{|l|}{ Perencanaan Kehamilan } \\
\hline 1. Direncanakan & 43 & 58,1 & 31 & 41,9 & 74 & 100 & \multirow[t]{2}{*}{$0,051 * *$} & \multirow{2}{*}{$\begin{array}{c}3,052 \\
(0,963-9,672)\end{array}$} \\
\hline 2. Tidak direncanakan & 5 & 31,2 & 11 & 68,8 & 16 & 100 & & \\
\hline \multirow{3}{*}{$\begin{array}{l}\text { Kelelahan fisik } \\
\text { 1. Tidak } \\
\text { 2. Ya }\end{array}$} & 27 & 67,5 & 13 & 32,5 & 40 & 100 & \multirow[t]{3}{*}{$0,016^{*}$} & \multirow{3}{*}{$\begin{array}{c}2,868 \\
(1,204-6,831)\end{array}$} \\
\hline & & & & & & & & \\
\hline & 21 & 42 & 29 & 58 & 50 & 100 & & \\
\hline \multirow{2}{*}{$\begin{array}{r}\text { Dukungan Keluarga } \\
\text { 1. Ada dukungan }\end{array}$} & 45 & 59,2 & 31 & 40,8 & 76 & 100 & \multirow[t]{3}{*}{$0,009 *$} & \multirow{3}{*}{$\begin{array}{c}5,323 \\
(1,371-20,657)\end{array}$} \\
\hline & & & & & & & & \\
\hline 2. Tidak ada dukungan & 3 & 21,4 & 11 & 78,6 & 14 & 100 & & \\
\hline \multirow{2}{*}{\multicolumn{9}{|c|}{$\begin{array}{l}\text { Pendidikan Ibu } \\
\text { 1. Pendidikan tinggi } \\
\text { (S1, D3, SLTA) }\end{array}$}} \\
\hline & & & & & & & & \\
\hline & 35 & 63,6 & 20 & 36,4 & 55 & 100 & \multirow[t]{2}{*}{$0,014 *$} & 2,962 \\
\hline $\begin{array}{l}\text { 2. Pendidikan rendah } \\
\text { (TS, SD, SMP) }\end{array}$ & 13 & 37,1 & 22 & 62,9 & 35 & 100 & & $(1,230-7,130)$ \\
\hline Pekerjaan Ibu & & & & & & & & \\
\hline 1. Tidak Bekerja & 39 & 51,3 & 37 & 48,7 & 76 & 100 & 0,371 & 0,586 \\
\hline 2. Bekerja & 9 & 64,3 & 5 & 35,7 & 14 & 100 & & $(0,180-1,910)$ \\
\hline
\end{tabular}

Tabel 2 menunjukkan hasil analisis Chi Square terdapat 6 variabel yang memiliki signifikansi terhadap kejadian Postpartum Blues yaitu Umur ibu $(p=0,036$; OR=2,929), paritas $(p=0,007 ; \quad$ OR=3,235), Komplikasi/penyulit persalinan $(p=0,037 ; \mathrm{OR}=2,451)$, kelelahan fisik $(p=0,016 ; \quad \mathrm{OR}=2,868), \quad$ dukungan keluarga 
$(p=0,009 ; \mathrm{OR}=5,323)$ dan pendidikan ibu $(p=0,014$; $\mathrm{OR}=2,962)$

Variabel-variabel kandidat yang memenuhi kriteria kandidat model multivariat adalah variabel yang bermakna secara statistik $(\mathrm{p}<0,05)$ dan variabel yang memiliki nilai $\mathrm{p}<0,25$ meliputi ; umur ibu, usia kehamilan, paritas, komplikasi/penyulit persalinan, kelelahan fisik, dukungan keluarga, pendidikan ibu dan perencanaan kehamilan.

Tabel 3. Model Akhir Analisis Multivariat Faktor yang Mempengaruhi kejadian Postpartum Blues di Kota Palembang

\begin{tabular}{lcccc} 
Variabel & Koefisien & p_value & \multicolumn{2}{c}{ OR $(95 \% \mathrm{CI})$} \\
\hline Paritas & 2,716 & 0,000 & 15,117 & $(3,821-59,805)$ \\
Dukungan keluarga & 2,398 & 0,009 & 10,996 & $(1,829-66,107)$ \\
Perencanaan Kehamilan & 2,289 & 0,006 & 9,863 & $(1,936-50,233)$ \\
Pendidikan & 1,296 & 0,023 & 3,656 & $(1,195-11,188)$ \\
Kelelahan Fisik & 1,206 & 0,029 & 3,341 & $(1,134-9,846)$ \\
Constant & $-3,800$ & 0,000 & & 0,034 \\
\hline
\end{tabular}

\section{PEMBAHASAN}

Hasil penelitian menunjukkan sebagian besar ibu primipara mengalami postpartum blues. Hal ini sejalan dengan penelitian terdahulu ${ }^{10,14,15}$ yang menunjukkan wanita primipara mempunyai risiko lebih besar terhadap postpartum blues. Ibu yang pernah melahirkan sebelumnya memiliki pengalaman dalam merawat bayinya dibandingkan ibu yang baru pertama kali melahirkan, primipara akan cenderung mengalami gangguan mood ringan. Pengalaman pertama kali menghadapi proses persalinan dan merawat anak sering kali memunculkan sikap yang beragam pada ibu primipara. Ibu berada dalam proses adaptasi dan belum berpengalaman dalam merawat anak, sehingga merasa menghadapi masalah sendiri. Oleh karena itu Ibu primipara membutuhkan orang-orang yang mendampingi dalam masa nifas, sehingga masa nifas akan dilewati dengan baik.

Hasil penelitian ini sejalan dengan penelitian sebelumnya yang menunjukkan terdapat pengaruh dukungan keluarga dengan terjadinya postpartum blues. ${ }^{16,17}$ Merawat bayi bukanlah tugas yang ringan, terutama bagi ibu baru, dalam asuhan pasca persalinan dukungan suami (keluarga) sangat diperlukan, karena keputusan suami dan arahan keluarga terutama ibu sangat berpengaruh dan menjadi acuan penting bagi ibu dalam merawat bayinya sehari-hari. Bila suami dan keluarga tidak memberikan dukungan, membuat ibu sedih dan kewalahan dalam mengasuh bayinya di hari-hari pertama pasca melahirkan.

Hasil penelitian diperoleh sebagian besar ibu yang tidak merencanakan kehamilan mengalami postpartum blues. Hasil penelitian ini sejalan dengan penelitian terdahulu yang menyatakan terdapat hubungan bermakna antara status kehamilan yang diinginkan dan tidak diinginkan dengan kejadian postpartum blues. ${ }^{18}$ Kehamilan merupakan proses alamiah yang menyenangkan, didambakan, dan diinginkan oleh setiap wanita sehingga perlu adanya kesiapan fisik dan psikologis. Kehamilan yang diharapkan akan membuat seorang wanita semakin siap dalam persalinan dan menjadi ibu. ${ }^{10}$ Persiapan yang baik membuat ibu postpartum akan mampu menghadapi masa pasca persalinannya dengan baik tanpa adanya gangguan syndrome postpartum.

Hasil penelitian menunjukkan bahwa pendidikan ibu sebagaian besar berpendidikan rendah mengalami postpartum blues. Hasil penelitian ini sejalan dengan penelitian dimana persentasi postpartum blues pada ibu yang memiliki pendidikan rendah (SD-SMP) adalah $54,5 \%$ dan $86,6 \%{ }^{15,18}$

Tingkat pendidikan sangat berpengaruh terhadap kecerdasan emosional, ibu yang memiliki tingkat pendidikan tinggi akan memiliki cara berfikir yang lebih rasional, dan semakin mudah untuk menerima informasi. Ibu yang tidak mendapatkan informasi yang memadai tentang kehamilan dan persalinan umunya akan sulit dalam menyesuaikan diri terhadap peran dan aktivitas barunya sehingga memungkinkan terjadinya gangguan psikologis seperti postpartum blues.

Hasil penelitian bahwa ibu yang mengalami kelelahan fisik lebih banyak mengalami postpartum blues. Hasil penelitian ini sejalan dengan penelitian sebelumnya dimana kelelahan fisik dapat memicu 
terjadinya postpartum blues. ${ }^{19}$ Adanya penambahan peran dan tanggung jawab baru ibu dalam perawatan bayi, proses persalinan lama yang tidak pernah dialami sebelumnya, kurang istirahat dan tidur dapat menyebabkan kelelahan fisik pada ibu. Kelelahan fisik juga disebabkan karena aktivitas mengasuh, menyusui, memandikan, mengganti popok, dan menimang bayi sepanjang hari bahkan tak jarang di malam hari, sehingga menguras tenaga dan menimbulkan kelelahan pada ibu, apalagi jika tidak ada bantuan dari suami atau anggota keluarga yang lain. ${ }^{20}$

Hasil penelitian diperoleh bahwa ibu yang berumur < 20 atau >35 tahun mengalami postpartum blues. Hasil penelitian ini sejalan dengan penelitian sebelumnya yang menyatakan bahwa kejadian postpartum blues lebih banyak dialami oleh wanita yang berumur $<20$ tahun atau $>35$ tahun ${ }^{16,18}$ Hasil penelitian oleh Ilmuwan dari Royal College of Obstetricians and Gynecologist, Inggris Raya, bahwa usia <17 tahun dan $>35$ tahun lebih berpotensi keguguran, operasi caesar, dan komplikasi saat kelahiran yang angkanya meningkat tajam setelah wanita berusia di atas 35 tahun. $^{21}$

Menurut peneliti, umur berkaitan dengan kesiapan ibu dalam proses kehamilan dan persalinan, umur juga mempengaruhi terjadinya masalah psikologis pada ibu postpartum. Secara umum pada usia di bawah 20 tahun memiliki pengetahuan yang terbatas tentang kehamilan atau

\section{KESIMPULAN DAN SARAN}

Angka kejadian postpartum blues di Kota Palembang ditemukan hanya sebagai, kondisi ini karena di salah satu rumah yang menjadi tempat penelitian tidak ada yang mengalami kejadian tersebu. Namun paritas merupakan faktor yang paling dominan penyebab postpartum blues. Terjadinya postpartum blues melibatkan faktorfaktor biopsikososial sebelum dan setelah bersalin.

\section{UCAPAN TERIMA KASIH}

Ucapan terimakasih peneliti sampaikan kepada direktur RSI Muhammadiyah,RS Bayangkara dan kurangnya informasi dalam mengakses pelayanan kesehatan yang ada. Selain itu pada usia tersebut juga belum cukup mencapai kematangan fisik, mental, peran dan aktivitas baru sebagai ibu dalam merawat anaknya sehingga mengalami kesulitan sendiri dalam beradaptasi, dibutuhkan pertolongan dari petugas kesehatan yang ada, dalam mendampingi ibu melewati masa nifas selama perawatan di rumah sakit. Pada usia tua, yang membuat menjadi resiko adalah faktor kelelahan dan keadaan anatomi tubuh yang sudah tidak baik lagi untuk hamil dan bersalin dan bila ibu sudah memiliki anak, membuat beban tersendiri bagi ibu, sehingga membawa masalah dalam masa nifasnya.

Hasil penelitian diperoleh bahwa ibu yang melahirkan dengan komplikasi/penyulit persalinan mengalami postpartum blues. Hasil analisis ini sejalan dengan penelitian sebelumnya dimana riwayat kehamilan dan persalinan dengan komplikasi dapat menjadi faktor pendukung terjadinya postpartum blues. ${ }^{6}$ Komplikasi persalinan seperti persalinan yang lama, Ketuban Pecah Dini, malpersentasi, hypertensi dalam kehamilan, serta intervensi medis yang digunakan selama proses persalinan diduga semakin memperbesar trauma fisik yang ditimbulkan pada saat persalinan, maka semakin besar pula trauma psikis yang muncul dan kemungkinan perempuan yang bersangkutan akan menghadapi depresi pasca persalinan.

Adanya kerentanan biologis, kerentanan psikologis, situasi stresful, dukungan sosial kurang, dan strategi yang maladaptif, bersama-sama memberi kontribusi bagi berkembangnya postpartum blues. Dibutuhkan dukungan sosial, emosional, informasi dan bantuan tenaga bagi ibu postpartum dan mengenali penyebab postpartum blues sejak awal.

RSI Khodijah, enumerator dan semua pihak yang telah membantu dalam menyelesaikan penelitian ini. 


\section{DAFTAR PUSTAKA}

1. Seyfried LS, Marcus SM. Postpartum mood disorders. Int Rev Psychiatry. 2003;15:23142. (PubMed) (Google Scholar)

2. Hapgood CC, Elkind GS, Wright JJ. Maternity blues: Phenomena and relationship to later postpartum depression. Aust N Z J Psychiatry. 1988;22:299-

306. (PubMed)(Google Scholar)

3. Lowdermilk, D.L., Perry, S.E., \& Bobak, I.M. 2000. Maternity women's health care. $7^{\text {th }}$ ed. St. Louis: Mosby.Inc

4. Perry, S.E., Hockenberry, M.J., Lowdermilk, D.L., \& Wilson, D. 2010. Maternal and Child Nursing Care, 1. 4th ed. Missouri: Mosby Elsevier.

5. Stone SD, Menken AE. 2008. Perinatal Mood Disorder: An Introduction. In Perinatal and Postpartum mood disorder: Perspectivesand Treatment guide for Health Care Practicioner. Springer Publishing Company,

6. Ratna. 2009. Perawatan pasca melahirkan. dari

http://ratnarespati.com/2009/03/03/perawatanpasca-melahirkan (diakses tanggal 28 Oktober 2017)

7. Freudenthal., Crost., M., \& Kaminski., M. (1999). Severe post-delivery blues: associated factors. Arch Womens Ment Health, No2, 3744

8. Olds, S.B., London, M.L., \& Ladewig, P.A.W. 2000. Maternal - newborn nursing a family and community- based approach. $6^{\text {th }}$ ed. New Jersey: Prentice Hall Health

9. Henshaw. 2003. Postnatal blues: A risk faktor of postnatal depression. J Pychosom Obstet Gynecol, 25, 267-272

10. Bobak, Laudermilk, Jensen, et al. 2005. Buku Ajar Keperawatan Maternitas. Jakarta: EGC

11. Joy, Saju. 2010. Postpartum Depression. Available from: http://reference.medscape.com/article/271662overview. (diakses 12 Nopember 2017)

12. Pignone MP, Gaynes BN, Rushton JL, et al. Screening for depression in adults : a summary of the evidence for the U.S. Preventive Services Task Force. Ann Intern Med. $2002 ; 136: 765-776$

13. Norwitz, E.R. \& Ali, U.E. 2009 Vacuumassisted vaginal delivery. Reviews in obstetrics and Gynecology, 2(1), 5-17

14. Wijayanti, K.,Wijayanti F A, Nuryanti E. 2013 Gambaran Faktor-Faktor Risiko Postpartum Blues Di Wilayah Kerja Puskesmas Blora. Jurnal Kebidanan, 2(5) Oktober 2013 ISSN.2089-7669

15. Desfanita, Misrawati' Arneliwati. 2015. Faktor-Faktor Yang Mempengaruhi Postpartum Blues. Program Studi Ilmu Keperawatan Universitas Riau JOM, 2(2).

16. Kurniasari D, Astuti YA. 2015.Hubungan Antara Karakteristik Ibu, Kondisi Bayi Dan Dukungan Sosial Suami Dengan Postpartum Blues Pada Ibu Dengan Persalinan SC Di Rumah Sakit Umum Ahmad Yani Metro Tahun 2014. Jurnal Kesehatan Holistik Volome 9, Nomor 3, Juli 2015:115-125

17. Benih, Ade, Nirwana. 2011. Psikologi Kesehatan Wanita. Yogyakarta : Nuha Medika

18. Irawati, D dan Yuliani, F. 2014. Pengaruh Faktor Psikososial dan Cara Persalinan Terhadap Terjadinya Post Partum Blues Pada Ibu Nifas. Hospital Majapahit (6) 1-7 Vol 6 No. 1

19. Jayasima, A M, Deliana SM, dan Mabruri, M I,. 2014. Postpartum Blues Syndrome Pada Kelahiran Anak Pertama Developmental and Clinical Psychology, Universitas Negeri Semarang ISSN 2252-6358. Dari http://journal.unnes.ac.id/sju/index.php/dcp (diakses tanggal 19 Nopember 2017)

20. Mansur, Herawati. 2009. Psikologi Ibu dan Anak untuk Kebidanan. Jakarta : Penerbit Salemba Medika.

21. Dian. (2012). Usia 20-35 tahun tepat untuk melahirkan. Fimelle.com; Woman Love \& Life. http://www.universitasgunadarma.com/ (diakses tanggal 6 Nopember 2019) 